\title{
What Physicians Know about Statistics in Saudi Arabia
}

\author{
Hella O. Alothman ${ }^{1 *}$, Emad Masuadi'2, Tariq Alothman ${ }^{3}$, Samiah Almehmadi', \\ Mohammed H. Alenazi ${ }^{3}$, Raghad Alothman ${ }^{4}$, Mazen S. Ferwana ${ }^{5}$
}

${ }^{1}$ Department of Family Medicine and Primary Health Care, King Abdulaziz Medical City, National Guard Health Affairs, Riyadh, KSA

${ }^{2}$ Department of Medical Education, College of Medicine, King Saud bin Abdulaziz University for Health Sciences, Riyadh, KSA

${ }^{3}$ Riyadh, KSA

${ }^{4}$ Medical College, Riyadh, KSA

${ }^{5}$ Family Medicine, King Saud bin Abdul-Aziz University for Health Sciences; National \& Gulf Center for Evidence Based Health Practice, King Abdullah International Medical Research Center, Family Medicine \& Primary Healthcare Department, King Abdul-Aziz Medical City, Ministry of National Guard-Health Affairs, Riyadh, KSA

Email: ^Hailah-O@hotmail.com, masudi.emad@yahoo.com, alothmantareq@yahoo.com, samiah-m@outlook.com, mohammedalenizi@yahoo.com,raghadksa27@hotmail.com

How to cite this paper: Alothman, H.O., Masuadi, E., Alothman, T., Almehmadi, S., Alenazi, M.H., Alothman, R. and Ferwana, M.S. (2020) What Physicians Know about Statistics in Saudi Arabia. Open Journal of Social Sciences, 8, 282-294.

https://doi.org/10.4236/jss.2020.81021

Received: December 21, 2019

Accepted: January 14, 2020

Published: January 17, 2020

Copyright $\odot 2020$ by author(s) and Scientific Research Publishing Inc. This work is licensed under the Creative Commons Attribution International License (CC BY 4.0).

http://creativecommons.org/licenses/by/4.0/

\begin{abstract}
Introduction: Statistics is a science that deals with collecting, managing, summarizing, and presenting data. An adequate understanding will help in making decisions [1]. Physicians were found to have limited knowledge of statistics. Objective: To assess the knowledge, familiarity, and competency of statistical concepts among physicians. Methods: It's a cross-sectional study that was conducted in Riyadh, Saudi Arabia. A convenient sample of 440 physicians was identified and contacted through a digital survey. A questionnaire was used to obtain statistical familiarity and competency among physicians. Results: This study found that more than half of the participants were interested in research with at least one publication. More than half learned statistics in undergraduate and postgraduate years. Physicians were found to have limited competency toward statistical concepts. Conclusion: Physicians were found to have sufficient information about the basic principles of statistics which are commonly used in medical research articles. Steps should be taken to educate trainees by conducting revisions, and statistical courses.
\end{abstract}

\section{Keywords}

Statistics, Calculation, Physicians, Saudi Arabia 


\section{Introduction}

Statistics is a science that deals with collecting, analyzing, and presenting data. On the other hand, familiarity and competency measured by the ability to acquaintance knowledge through sensory input plus the ability to practice this knowledge, are "a combination of sensory input-familiarity and output - competency" [1] [2] [3] [4].

Clinicians report a low level of confidence and negative attitude towards statistics. Despite the fact, undergraduate medical schools and postgraduate education curriculum involve statistical courses but, still, many people feel deficit, stress, and frustration in calculation; affect their competence in statistics [4] [5] [6] [7] [8].

To elaborate more, a study reported $69 \%$ cannot understand and explain to others, and $79 \%$ are unable to critically appraise research. A research review found one-fourth concluding i.e.: wrong interpretation in research, ignoring the sample size, data distribution, incorrect summary, measurement, and choosing the wrong statistical test [8] [9].

Multiple articles have been observed that many medical professionals have a negative attitude toward statistics and are unable to interpret basic as well as advanced statistical concepts. But, no articles find the gap between physician familiarity and competency to answer correctly [9] [10] [11].

They need to be aware of this diversity in familiarity, and competency is a necessity for growth in a medical environment where the end product is well-trained collaborative science, scientists and funded research.

This study aims to assess the familiarity and competency of statistical concepts among physicians in Saudi Arabia.

\section{Method}

The frame was a cross-sectional study, convenience sampling used to identified population include (program directors, trainers, and residents, general practitioner), and an electronic survey conducted using the "Survey Monkey" platform [Appendix 1] in each hospital by their email addresses in six governmental local hospitals in Saudi Arabia, Riyadh beginning of December in 2018 till end of February in 2019.

A questionnaire [Appendix 1] was structured, and pre-tested in a pilot study on a sample of 20 participants then finalized. Results of the piloted questionnaires were not included in the analysis and validated by two statistician authors.

The survey includes three basic sections: the demographics, familiarity toward statistics, and competency of statistical concepts, consist of 13 basic and advance statistical questionnaire.

The first section involved personal data. The second part addressed perception familiarity questions preformed on a five-point scale, range (extremely familiar till not familiar at all). The last section involved questions on statistical knowledge in the form of statistical calculation. 


\section{Statistical Analysis:}

Participant characteristics described by tabulation, frequency, and proportions. For analysis purposes the familiarity Likert-scale was dichotomized as "Not familiar" or "Familiar" with the two categories of "Moderately familiar" and "Extremely familiar" being allocated to "Familiar. We analyzed and compared by McNemar"s test of proportion ("Number of Familiarity" and "Correct answer of knowledge-based questionnaire"). A p-value of 0.000 used for statistical significance. SPSS version 24 used for analysis.

Patient and Public Involvement:

No patient involved.

\section{Results}

A total of 440 participants, full respond through their email. Show equal gender participation, with different medical specialties in Table 1.

More than half of participants showed their interest in conducting research, more than half of them conducted research as co-authors and $38 \%$ as principle investigator, less in data collection, data entry, and analysis process. From the total participants; more than a quarter published at least two articles.

Table 2 shows: half of them learned statistics in their undergraduate and postgraduate years. Around two-fifth enrolled in biostatistics courses as: research method, Evidence-based medicine, YouTube sessions, and less in statistical books.

Table 1. Baseline characteristics of the study participants $(\mathrm{N}=440)$.

\begin{tabular}{|c|c|c|c|}
\hline \multirow{3}{*}{$\begin{array}{c}\text { Variable Demographic data }(n=440) \\
\text { Gender }\end{array}$} & \multirow{3}{*}{$\begin{array}{c}\text { Categories } \\
\text { Female } \\
\text { Male }\end{array}$} & \multicolumn{2}{|c|}{ N/440 (\%) } \\
\hline & & 225 & $(51.1)$ \\
\hline & & 215 & $(48.9)$ \\
\hline \multirow{3}{*}{$\begin{array}{l}\text { Age groups } \\
\text { (Years) }\end{array}$} & $\geq 25$ & 94 & $(21.4)$ \\
\hline & $30-26$ & 232 & $(52.7)$ \\
\hline & $31+$ & 114 & $(25.9)$ \\
\hline \multirow{4}{*}{ Nationality } & Saudi & 408 & $(92.7)$ \\
\hline & Non-Saudi & 32 & $(7.3)$ \\
\hline & 1 & 64 & $(14.5)$ \\
\hline & 2 & 63 & $(14.3)$ \\
\hline \multirow{6}{*}{ (Years) of Graduation from Medical School } & 3 & 85 & $(19.3)$ \\
\hline & 4 & 57 & (13) \\
\hline & 5 & 48 & $(10.9)$ \\
\hline & $6+$ & 123 & (28) \\
\hline & MBBS & 110 & (25) \\
\hline & $\mathrm{PhD} /$ Master & 26 & $(5.9)$ \\
\hline \multirow[t]{3}{*}{ Certificate\Highest degree } & Resident & 205 & $(46.6)$ \\
\hline & Board Certified & 77 & $(17.5)$ \\
\hline & Consultant & 22 & (5) \\
\hline
\end{tabular}




\section{Continued}

\begin{tabular}{cccc}
\hline & 1 & 135 & $(30.7)$ \\
How many years from last highest degree/certificate & 2 & 123 & $(28)$ \\
& 3 & 83 & $(18.9)$ \\
& $4+$ & 99 & $(22.5)$ \\
& Family Medicine & 165 & $(37.5)$ \\
& Internal Medicine & 57 & $(13)$ \\
& Surgery & 67 & $(15.2)$ \\
& Emergency & 21 & $(4.8)$ \\
& Pediatric & 41 & $(9.3)$ \\
& Ob/Gyn & 14 & $(3.2)$ \\
& Pathology/Radiology & 11 & $(2.5)$ \\
& General Practitioner & 39 & $(8.9)$ \\
& Other specialties & 25 & $(5.7)$ \\
\hline
\end{tabular}

Table 1: Shows the years since graduation from medical school, $28 \%$ of the study physicians had graduated more than 6 years ago while 19.3\% graduated recently i.e. 1 - 3 years back. Among them, 30.7\% took the last highest qualification within the last one-year time frame, $28 \%$ in the past two years and the rest of the participants received the highest certification more than three years back.

Table 2. Sources of knowledge about statistics.

\begin{tabular}{ccc}
\hline Source of knowledge & \multicolumn{2}{c}{ N/440 (\%) } \\
\hline Undergraduate & 285 & $(65)$ \\
Postgraduate & 273 & $(62)$ \\
Extra curriculum long-term course $>$ 5 days & 118 & $(27)$ \\
Watching statistical YouTube sessions non-systematically & 113 & $(26)$ \\
Reading a statistical book & 94 & $(21)$ \\
Extra curriculum short-term course < 5 days & 63 & $(14)$ \\
Extra curriculum short-term online course < 5 days & 20 & $(5)$ \\
Extra curriculum long-term online course $>$ 5 days & 16 & $(4)$ \\
\hline
\end{tabular}

Table 2: Regarding the source of knowledge gain; more than half $65 \%$ - $62 \%$ learned statistics during their undergraduate and postgraduate period respectively, plus $27 \%$ from long-term courses for more than 5 days. Around $41 \%$ enrolled in Biostatistics courses like Research method, EBM domain, others (21\%) chose to read statistical books.

The main aim is to assess the familiarity towards different statistical concepts in Figure 1 showing: 50\% familiar to basic concepts in -Descriptive Statisticsincludes (Scales of measurement, Graphical exploration of data, characteristics for a variable). And less than one-third familiar to advance statistical concepts include (Estimation, Confidence interval, hypothesis testing principle, Power analysis).

Figure 2 showed competency and understanding in answering different level of a questionnaire: half of them they understand the basic knowledge of statistics 


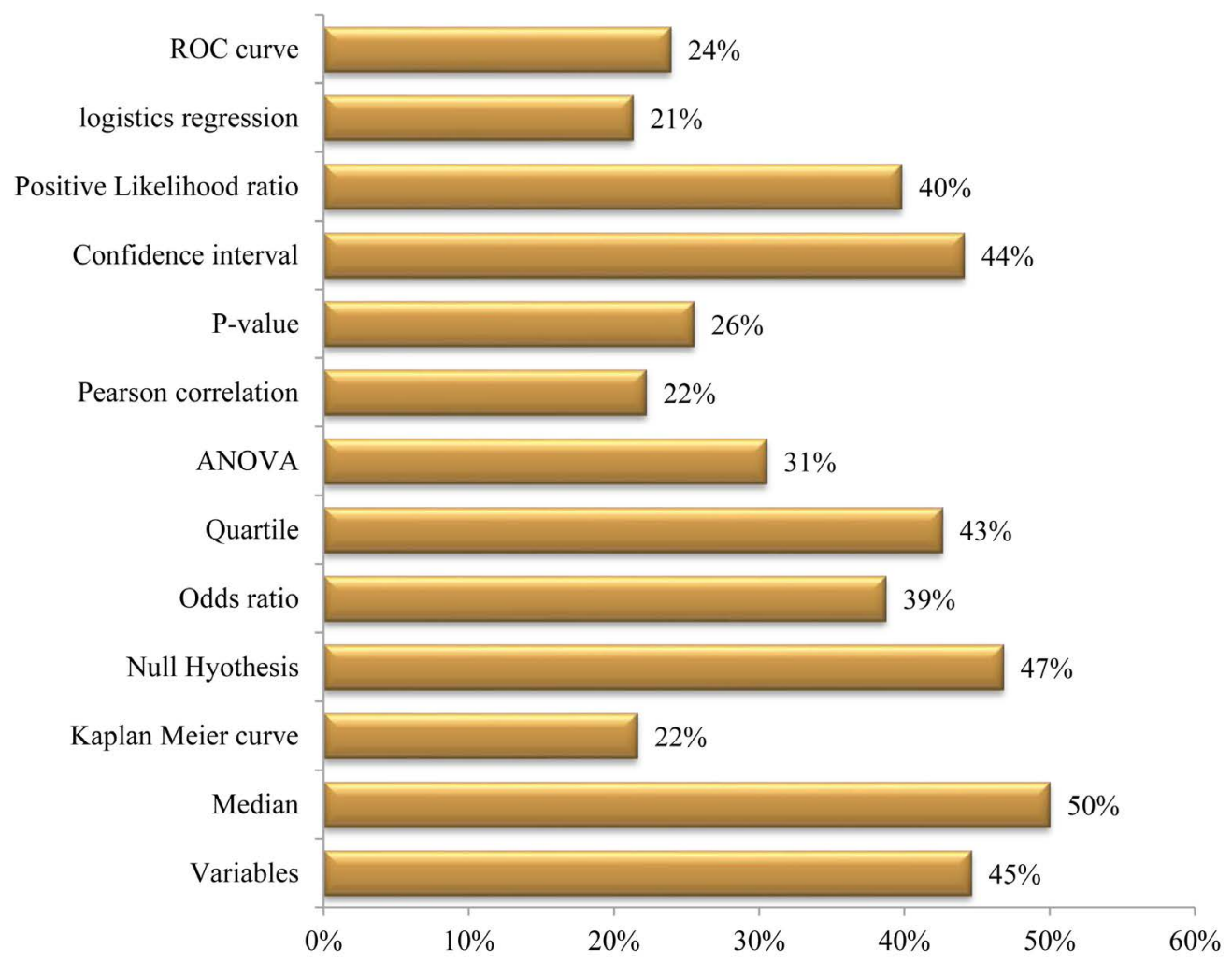

Figure 1. Familiarity towards different statistical concepts. Show understanding of participates towards statistical concepts; $50 \%$ were found to be familiar to median, $47 \%$ null hypothesis, $45 \% \mathrm{knew}$ about variables, confident interval was understood by $44 \%$, the rest of statistical concepts were perceived by less than $40 \%$ of the study population.

in a simple calculation, around two-fifth answer correctly in advance statistics questionnaire.

In the last part of the analysis we found the gap difference between statistical familiarity concepts toward corrected answers in Table 3: represent the gap difference between statistical familiarity concepts toward corrected answers: that means $(-47 \%)$ underestimated their knowledge and their ability to answer correctly, were (19\%) confident to their knowledge and able to answer correct.

\section{Discussion}

The result of this convenient sample includes medical program directors, trainees and residents concluded; that they know better than they think about statistics especially basic concepts but, in an advance statistics was poor; same reference to competency questions. Interestedly more than half of them had at least one published research. Moreover, the gap difference between attitudes perception towards number corrected answers showed that the majority of participants underestimated themselves as a result of previous negative understanding, experience, and practice.

To review more statistical concepts; median concept in the present study was more prevalent in both familiarity and competency as well as in variables. While 
ROC curve is a plot for (1-specificity \& sensitivity)

When to use binary logistic regression (when the outcome variable has only 2 categories)

In diagnostic study, the result shows 38\% sensitivity, and 69\% specificity;Positive likelihood ratio= $(1.2258)$

Which one of Confidence interval is the widest in (99\%)

The p-value means (Probability to reject the null hypothesis when it's true )

When to use Pearson correlation coefficient in (measure association between two numerical)

ANOVA is ( To compare mean between different groups)

What is the first Quartile (splits off the lowest 25\% of data from the highest 75\%)

From previous image calculate the odds ratio $(2 * 4) /(2 * 2)=$

If you reject the null hypothesis at $10 \%$ then (It could be rejected or acepted at $5 \%$ )

The previous image stand for (kaplan Meier curve)

Find the median $(3,4,2,1,6,9,7)$

Which one of the variable is numerical (Gender, BMI, Nationality, specialty)
$28 \%$
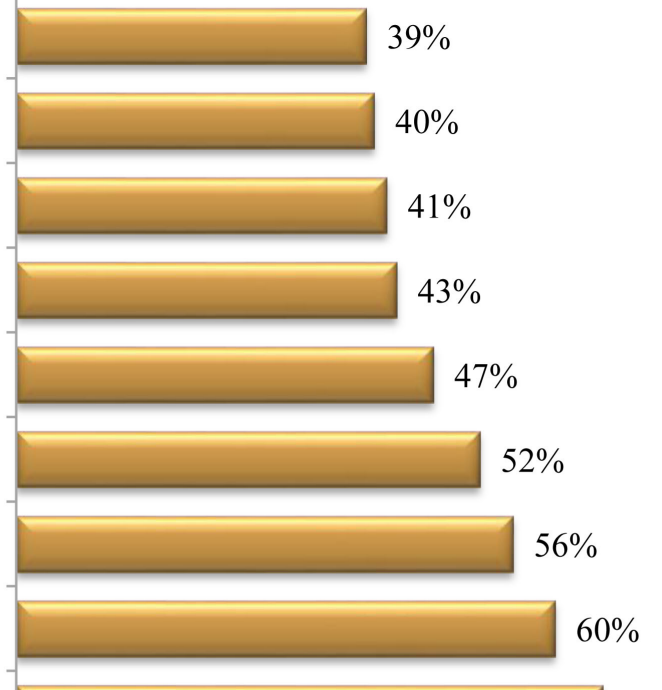

$66 \%$

$69 \%$

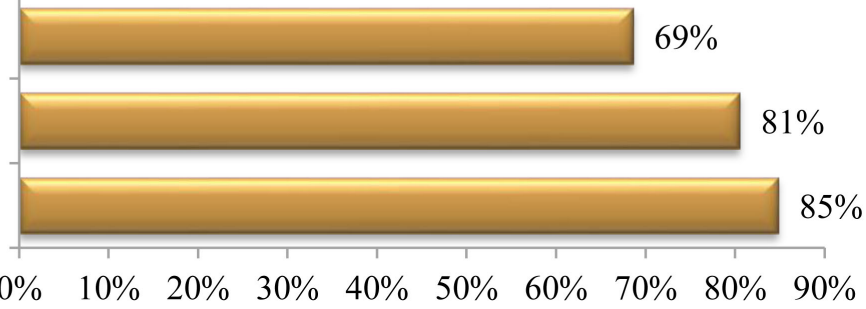

Figure 2. Percentage of correct answers for the knowledge questions. Demonstrate the proportion of study participants according to the correct answers given about statistical methods. It showed that $85 \%$ gave correct answers about variables, $81 \%$ knew median, 69\% recognized Kaplan-Meier curve image, $66 \%$ had knowledge about null hypothesis and $60 \%$ could calculate of odd ratio, $56 \%$ knew the meaning of first Quartile and 52\% had used ANOVA. The rest of 6 questions regarding (P-value, Confidence interval, likelihood ratio, Pearson correlation coefficient, binary logistic regression, ROC curve) had lowest correct answer by $\leq 47 \%$ participants.

Table 3. Gap difference between familiarity towards number of corrected answers.

\begin{tabular}{ccccccc}
\hline & \multicolumn{2}{c}{$\begin{array}{c}\text { N of familiarity } \\
\text { /440 (\%) }\end{array}$} & $\begin{array}{c}\text { N of knowledge } \\
\text { /440 (\%) }\end{array}$ & Difference & P-value \\
\hline Variables & 196 & $(44.5)$ & 373 & $(84.8)$ & $-40 \%$ & $<0.001$ \\
Median & 233 & $(53)$ & 354 & $(80.5)$ & $-28 \%$ & $<0.001$ \\
Null Hypothesis & 206 & $(46.8)$ & 244 & $(55.5)$ & $-9 \%$ & 0.003 \\
P-value & 112 & $(25.5)$ & 182 & $(41.4)$ & $-16 \%$ & $<0.001$ \\
Confidence interval & 194 & $(44.1)$ & 288 & $(65.5)$ & $-21 \%$ & $<0.001$ \\
Quartile & 190 & $(43)$ & 244 & $(56)$ & $-13 \%$ & $<0.001$ \\
Odds ratio & 170 & $(38.6)$ & 265 & $(60.2)$ & $-22 \%$ & $<0.001$ \\
Pearson correlation & 98 & $(22.3)$ & 205 & $(46.6)$ & $-24 \%$ & $<0.001$ \\
Logistics regression & 94 & $(21.4)$ & 172 & $(39.1)$ & $-18 \%$ & $<0.001$ \\
Kaplan Meier curve & 95 & $(21.6)$ & 302 & $(68.6)$ & $-47 \%$ & $<0.001$ \\
\hline
\end{tabular}


Continued

\begin{tabular}{ccccccc}
\hline Likelihood Ratio & 260 & $(59.1)$ & 176 & $(40)$ & $19 \%$ & $<0.001$ \\
ROC curve & 105 & $(23.9)$ & 122 & $(27.7)$ & $-4 \%$ & 0.281 \\
ANOVA & 134 & $(30.5)$ & 228 & $(51.8)$ & $-21 \%$ & $<0.001$ \\
\hline
\end{tabular}

Table 3: Represent the gap difference between statistical familiarity concepts toward corrected answers: that means $(-47 \%)$ minimize their knowledge and their ability to answer correct, were (19\%) confident to their knowledge and ability to answer correctly.

in null hypothesis, familiarity was weak but higher in competency question. The similar result obtained for Confident interval, likelihood ratio, number needed to treat, ANOVA, odd ratio, Kaplan Meier curve, and Pearson correlation.

Understanding of logistic regression was also low in familiarity and competency. Which it happened to ROC (receiver operating curve), even though it's part of sensitivity and specificity; the participants are familiar to both concepts in an individual way; but, as a whole concept, they were confused. The same thing happened to P-value concept which is commonly used in articles.

Multiple articles show fair understanding of statistical concepts; suggesting that the problem is not specific to particular specialty but it's an endemic issue within medical education. Further analysis, the mean correct answers of our participants to a statistics questionnaire scores more than half; which is not influenced by gender, years elapsed from graduation, other advanced degrees, or year of study [9] [12] [13] [14] [15] [16].

Despite that, the majority of participants have attended statistical training during undergraduate medical school, and postgraduate it should consider, similar finding in other studies [7] [8] [13]. These reports used different sets of questions compared to this study, thus hindering direct comparisons.

A study showed $76.7 \%$ clinicians were unable to identify appropriate statistical tests and $72 \%$ were not confident in designing their own study. Other articles report higher familiarity with statistical concepts, and low in competency questions [9] [10] [11] [12] [13].

This goes with a study: suggested that independent courses in statistics are unlikely to resolve clinicians' research abilities and skills. In contrast, the integrating approach of statistics and research methods will positively affect clinicians' research abilities and patient care decisions [17] [18].

This study presented important findings of the understanding of physicians in statistics to the existing pool of knowledge that many of the clinicians have knowledge about basic statistics at least to the level of it commonly used in research articles.

But, challenges expected: A recent systematic review proved; the complex of applying for such programs, limited effectiveness of many journal clubs, and motivated trainee [9] [10]-[21].

Another obstacle: to asses knowledge of the statistical concept that claims it measured by one simple question; a correct answer to one question does not prove that the concept is fully understood. As what an English historian Edward Gibbon said "the laws of probability so true in general so fallacious in particular" 
[19].

This highlights the importance of planning and implementing new interactive, integrated, and self-directed policies [9] [10]-[21].

To the best of our knowledge, the present study is the first to investigate statistical concepts in health care professionals in different specialties, with varying lengths of time since qualification and levels, and a good number in feedback.

Discussion, revision, and open ended questions are encouraged in journal clubs, research projects, and self-directed learning to minimize their hesitancy towards statistical practices.

\section{Conclusion}

Many of these clinicians were competent. But; there was a gap between competence and familiarity. Therefore, various strategies are required to enhance their confidence in statistical interpretations such as practical courses, involvement in research work, data analysis, improving teaching methods, and software skills. This will benefit in a medical decision relevant to clinical practice and for academic career growth.

\section{Limitation}

This study is limited to self-selected physicians in Riyadh, Saudi Arabia; these results cannot be generalized on the national level but, it was an initiative to highlight the issue. Another issue is response bias and multiple statistical testing.

\section{Strengths and Limitations of This Study}

- It's a cross-sectional study: descripted plus analytic; by assessing the association between different questioners.

- Show prevalence of statistical knowledge in Saudi Arabia.

- First to investigate statistical concepts in health care professionals in different specialties, with varying lengths of time since qualification and levels, with good number in feedback.

- This study limited to self-selected physicians (representatives).

\section{Practical Implications}

- Physicians were found to have limited knowledge of statistics.

- Higher familiarity with statistical concepts, and low in competency questions.

- Minimize their hesitance towards statistics by conducting interactive session, and enhance their confidence.

\section{Acknowledgements}

To my family for their love, patience, and encouragement.

\section{Contributorship Statement}

- Hella O. Alothman, Contributions to conception \& design of the work, in- 
terpretation \& analysis of data, AND Drafting the work, AND Final approval of the version to be published, AND Agreement to be accountable for all aspects of the work in ensuring that questions related to the accuracy or integrity of any part of the work are appropriately investigated and resolved.

- Emad Masuadi, Design of the work, interpretation of data.

- Tariq Al Othman, Acquisition, Data collection, analysis data, and proofreading.

- Samiah Almehmadi, Assistant in data, review.

- Mohammed H. Alenazi, data, and proofreading.

- Raghad AlOthman, Data collection, analysis data, drafting.

- Mazen S. Ferwana, Supervisor, Participating Investigators.

\section{Funding}

The authors declare that they have no funding.

\section{Conflicts of Interest}

The authors declare that they have no conflict of interests.

\section{References}

[1] Winters, R., Winters, A. and Amedee, R. (2010) Statistics: A Brief Overview. Ochsner Journal, 10, 213-216.

[2] Gervais, J. (2016) The Operational Definition of Competency-Based Education. JCBE, 1, 98-106. https://doi.org/10.1002/cbe2.1011

[3] Welty, L.J., Carter, R.E., Finkelstein, D., Harrell, F.E., Lindsell, C.J., Macaluso, M., et al. (2013) Perspective: Strategies Developing Biostatistics Resource in an Academic Health Center. Academic Medicine, 88, 454-460. https://doi.org/10.1097/ACM.0b013e31828578ed

[4] Hadley, J.A., Wall, D. and Khan, K.S. (2007) Learning Needs Analysis to Guide Teaching Evidence-Based Medicine: Knowledge and Beliefs amongst Trainees from Various Specialties. BMC Medical Education, 7, Article No. 11. https://doi.org/10.1186/1472-6920-7-11

[5] Hannigan, A., Hegarty, A.C. and McGrath, D. (2014) Attitudes towards Statistics of Graduate Entry Medical Students: The Role of Prior Learning Experiences. BMC Medical Education, 14, Article No. 70. https://doi.org/10.1186/1472-6920-14-70

[6] West, C.P. and Ficalora, R.D. (2007) Clinician Attitudes toward Biostatistics. MFMER, 82, 939-943. https://doi.org/10.4065/82.8.939

[7] Polychronopoulou, A., Eliades, T., Taoufik, K., Papadopoulos, M.A. and Athanasiou, A.E. (2010) Knowledge of European Orthodontic Postgraduate Students on Biostatistics. EJO, 33, 434-440. https://doi.org/10.1093/ejo/cjq098

[8] Windish, D.M., et al. (2007) Medicine Residents' Understanding of the Biostatistics and Results in the Medical Literature. JAMA, 5, 10-22. https://doi.org/10.1001/jama.298.9.1010

[9] Taylor, R.S., Ewings, P.E. and Taylor, R.J. (2004) Critical Appraisal Skills Training for Health Care Professionals: A Randomized Controlled Trial. BMC Medical Education, 7, Article No. 30. https://doi.org/10.1186/1472-6920-4-30 
[10] Alzahrani, S.H. and Aba Al-Khail, B.A. (2015) Resident Physician's Knowledge and Attitudes toward Biostatistics and Research Methods Concepts. Saudi Medical Journal, 36, 1236-1240. https://doi.org/10.15537/smj.2015.10.11842

[11] Bashir, M., Tariq, W. and Humariya, M. (2016) Assessment of Basic \& Advance Knowledge of Biostatistics and Clinical Research among Medical Practitioners at KFMC. Journal of Biometrics \& Biostatistics, 10, 3 .

[12] Msaouel, P., Kappos, T., Tasoulis, A., Apostolopoulos, A.P., Lekkas, I., Tripodaki, E.-S. and Keramaris, N.C. (2014) Assessment of Cognitive Biases and Biostatistics Knowledge of Medical Residents: A Multicenter, Cross-Sectional Questionnaire Study. Medical Education Online, 19, Article ID: 23646. https://doi.org/10.3402/meo.v19.23646

[13] Best, A.M. and Laskin, D.M. (2013) Oral and Maxillofacial Surgery Residents Have Poor Understanding of Biostatistics. International Journal of Oral and Maxillofacial Surgery, 71, 227-234. https://doi.org/10.1016/j.joms.2012.03.010

[14] Bookstaver, P.B., Miller, A.D., Felder, T.M., Tice, D.L., Norris, L.B. and Sutton, S.S. (2012) Assessing Pharmacy Residents' Knowledge of Biostatistics and Research Study Design. Annals of Pharmacotherapy, 46, 991-999. https://doi.org/10.1345/aph.1Q772

[15] Looney, S.W., Grady, C.S. and Steiner, R.P. (1998) An Update on Biostatistics Requirements in US Medical Schools. Academic Medicine, 73, 92-94. https://doi.org/10.1097/00001888-199801000-00018

[16] Guyatt, G., Cook, D. and Haynes, B. (2004) Evidence Based Medicine Has Come a Long Way. BMJ, 329, 990-991. https://doi.org/10.1136/bmj.329.7473.990

[17] Ille, T.M., Muthukrishnan, R. and Ille, M.E. (2017) Integrating Medical Biostatistics into Postgraduate Medical Curriculum. The National Medical Journal of India, 30, 212. https://doi.org/10.4103/0970-258X.218676

[18] Gibbon, E. (1869) The Autobiography and Correspondence of Edward Gibbon the Historian. Alex. Murray \& Son, London.

[19] Feldstein, D.A., Maenner, M.J., Srisurichan, R., Roach, M.A. and Vogelman, B.S. (2010) Evidence-Based Medicine Training during Residency: A Randomized Controlled Trial of Efficacy. BMC, 10, Article No. 59. https://doi.org/10.1186/1472-6920-10-59

[20] Khan, K.S. and Coomarasamy, A. (2006) A Hierarchy of Effective Teaching and Learning to Acquire Competence in Evidenced-Based Medicine. BMC Medical Education, 6, Article No. 59. https://doi.org/10.1186/1472-6920-6-59

[21] Weiss, S.T. and Samet, J.M. (1980) An Assessment of Physician Knowledge of Epidemiology and Biostatistics. Journal of Medical Education, 55, 692-697. https://doi.org/10.1097/00001888-198008000-00007 


\section{Appendix 1: Questionnaire}

1) What is your Gender: Female Male

2) What is your age ................ years

3) What is Nationality

4) Years of graduation from medical school years

5) Highest certification;

$\begin{array}{lll}\text { MBBS } & \text { Resident } & \text { Board certified } \\ \text { Master } & \text { Consultant } & \text { PhD }\end{array}$

other (specify)

6) How many years from the last highest last degree/Certification years

7) What is your specialty

8) Your interest in research

Very interested somehow interested Not interested

9) Did you participate in research as ....

$\begin{array}{lll}\text { Principle investigator } & \text { Co-author } & \text { Data analysis } \\ \text { Data collection } & \text { None } & \end{array}$

other .....

10) How many publication do you have

11) What the source for your statistical knowledge

Undergraduate postgraduate

Extra curriculum long-term course $>5$ days

Extra curriculum short-term course $<5$ days

Extra curriculum long-term online course $>5$ days

Extra curriculum short-term online course $<5$ days

Reading a statistical book

Watching statistical YouTube session non-systematically other (please specify)

12) What was the course domain (name):

Public health Epidemiology

Evidence based medicine

Research methodology Biostatistics Health informatics

Bio-informatics other (please specify)

13) To what extend you consider yourself familiar with the following statistics concept:

\begin{tabular}{|c|c|c|c|c|c|}
\hline Statistical concepts & Not Familiar & $\begin{array}{l}\text { Slightly } \\
\text { Familiar }\end{array}$ & $\begin{array}{l}\text { Somewhat } \\
\text { Familiar }\end{array}$ & $\begin{array}{l}\text { Moderately } \\
\text { Familiar }\end{array}$ & $\begin{array}{c}\text { Extremely } \\
\text { Familiar }\end{array}$ \\
\hline \multicolumn{6}{|l|}{ Variables } \\
\hline \multicolumn{6}{|l|}{ Median } \\
\hline \multicolumn{6}{|l|}{ Null hypothesis } \\
\hline \multicolumn{6}{|l|}{$P$-value } \\
\hline Confident interval & & & & & \\
\hline Odd ratio & & & & & \\
\hline
\end{tabular}




\section{Continued}

person correlation

logistic regression

Kaplan-Meier curve

likelihood ratio

ROC curve

ANOVA

Quartile

14) Which one of the variable is numerical:

a) Gender

b) BMI

c) Nationality

d) specialty

15) Find the median; 3, 4, 2, 1, 6, 9, 7

a) 9

b) 7

c) 4

16) What is the first quartile:

a) splits off the lowest $25 \%$ of data from the highest $75 \%$

b) cuts data set $>50 \%$

c) splits off the highest $50 \%$ of data from the lowest $25 \%$

17) Which one of Confidence interval is the widest:
a) $90 \%$
b) $95 \%$
c) $98 \%$
d) $99 \%$

18) If you reject the null hypothesis at $10 \%$ then:

a) It will be reject at $5 \%$

b) It could be rejected or accepted at $5 \%$

c) It can't be reject at $5 \%$

19) The p-value means:

a) Probability to reject the null hypothesis when it's true.

b) Chance of accept null hypothesis when it's true.

c) Probability of reject alternative when it's true.

20) Calculate the odd ratio (from image):

a) 2

b) 8

c) 16

\begin{tabular}{ccc}
\hline Risk & Disease \\
\hline & Yes & NO \\
\hline smoker & 4 & 2 \\
Non-smoker & 2 & 2 \\
\hline
\end{tabular}


21) When to use Pearson correlation coefficient in:

a) measure association between two categorical.

b) measure association between two numerical.

c) measure association between categorical and numerical.

22) When to use binary logistic regression:

a) when outcome variable is continues.

b) when outcome variable is more than 2 category.

c) when the outcome variable is numerical.

d) when the outcome variable is only 2 category.

23) This image stand for which of following:

a) Kaplan-Meier curve

b) kappa curve

c) forest plot

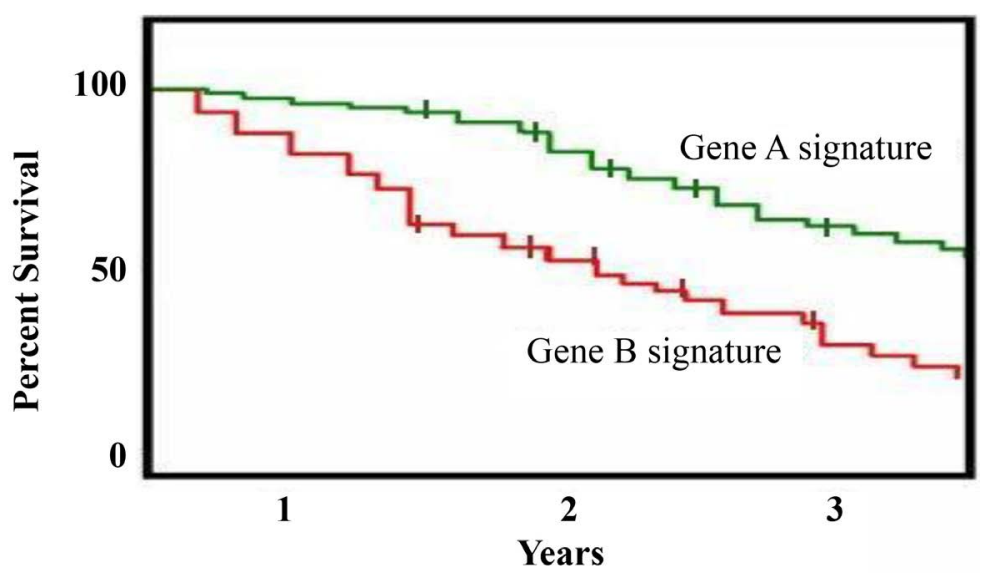

24) In a diagnostic study the result shows $38 \%$ sensitivity, and $69 \%$ specificity. Find the positive likelihood ratio:
a) 0.5362
b) 0.5588
c) 0.3422
d) 1.2258

25) ROC curve is a plot for:

a) (1-specificity).

b) X, Y-axis are sensitivity.

c) (1-specificity \& sensitivity)

26) ANOVA is:

a) To measure frequency in multiple data.

b) To compare prevalence between different groups.

c) To compare mean between different groups. 